\title{
An orphan disease: IgG4-related spinal pachymeningitis: report of 2 cases
}

\author{
Bishan D. Radotra, MD, ${ }^{1}$ Ashish Aggarwal, DNB, $\mathrm{MCh},{ }^{2}$ Ankur Kapoor, MS, $\mathrm{MCh},{ }^{2}$ \\ Navneet Singla, MS, $M C^{2}{ }^{2}$ and Debajyoti Chatterjee, MD $^{1}$
}

\begin{abstract}
Departments of ${ }^{1}$ Histopathology and ${ }^{2}$ Neurosurgery, Postgraduate Institution of Medical Education and Research, Chandigarh, India
\end{abstract}

\begin{abstract}
IgG4-related disease is relatively new disease entity and a rare one, and our knowledge of this entity continues to evolve. It was first described in the pancreas and since then has been described in virtually every organ. Spinal involvement resulting in pachymeningitis is rare, and there are only 8 reported cases of the same to date, with the cervicothoracic spine being the most commonly affected region.

The authors describe 2 cases in which the patients presented with spinal compression resulting in myeloradiculopathy (Case 1) and radiculopathy (Case 2). Imaging of spine in both cases revealed an ill-defined contrast-enhancing lesion at the lumbar level. Preoperatively, a diagnosis of spinal tumor was made, but intraoperatively no spinal tumor was found. The diagnosis was established histopathologically.

The disease has no particular defining features clinically or radiologically and can mimic common spinal tumors. It is important to accurately diagnose this rare entity because of its multisystem involvement and progressive course. Strict treatment guidelines have yet to be formulated. Although histologically this disease can mimic other inflammatory conditions, the presence of storiform fibrosis and an increased number of lgG4-positive plasma cells can help in clarifying the diagnosis.
\end{abstract}

http://thejns.org/doi/abs/10.3171/2016.4.SPINE1674

KEY WORDS IgG4; pachymeningitis; spinal; intradural; spinal compression

$\mathrm{T}$ HE newly recognized fibroinflammatory condition IgG4-related disease is characterized by tumefactive lesions, a dense lymphoplasmacytic infiltrate rich in IgG4-positive plasma cells, storiform fibrosis, and, often but not always, elevated serum IgG4 concentration..$^{10}$ Because it is a relatively newly recognized entity, the picture of IgG4-related disease continues to evolve in the published reports. Even the nomenclature is still evolving, the latest to be adopted being IgG4-related disease. ${ }^{11}$ This disease was initially described in the pancreas. In the last decade or so as the disease had been diagnosed with increased frequency clinically, it has been described in virtually every organ system: the biliary tree, salivary glands, periorbital tissues, kidneys, lungs, lymph nodes, meninges, aorta, breast, prostate, thyroid, pericardium, and skin. ${ }^{3,4,6-8}$ The treatment guidelines are being continually modified.
We report 2 cases of spinal pachymeningitis due to IgG-related disease. The presentation was like any other intradural spinal lesion. Although the intraoperative features were not typical of a spinal tumor, the final diagnosis was clinched on histopathology.

\section{Case Reports}

\section{Case 1}

A 50-year-old man presented with a 6-month history of progressive bilateral lower-limb weakness. He had wasting of lower limbs and difficulty in voiding for 3 months. Examination revealed significant atrophy and Grade 3/5 weakness in the lower limbs bilaterally.

Magnetic resonance imaging (Fig. 1) revealed an ill-defined intradural lesion at L1-2 that was isointense on T1weighted imaging (T1WI), hypointense on T2-weighted 

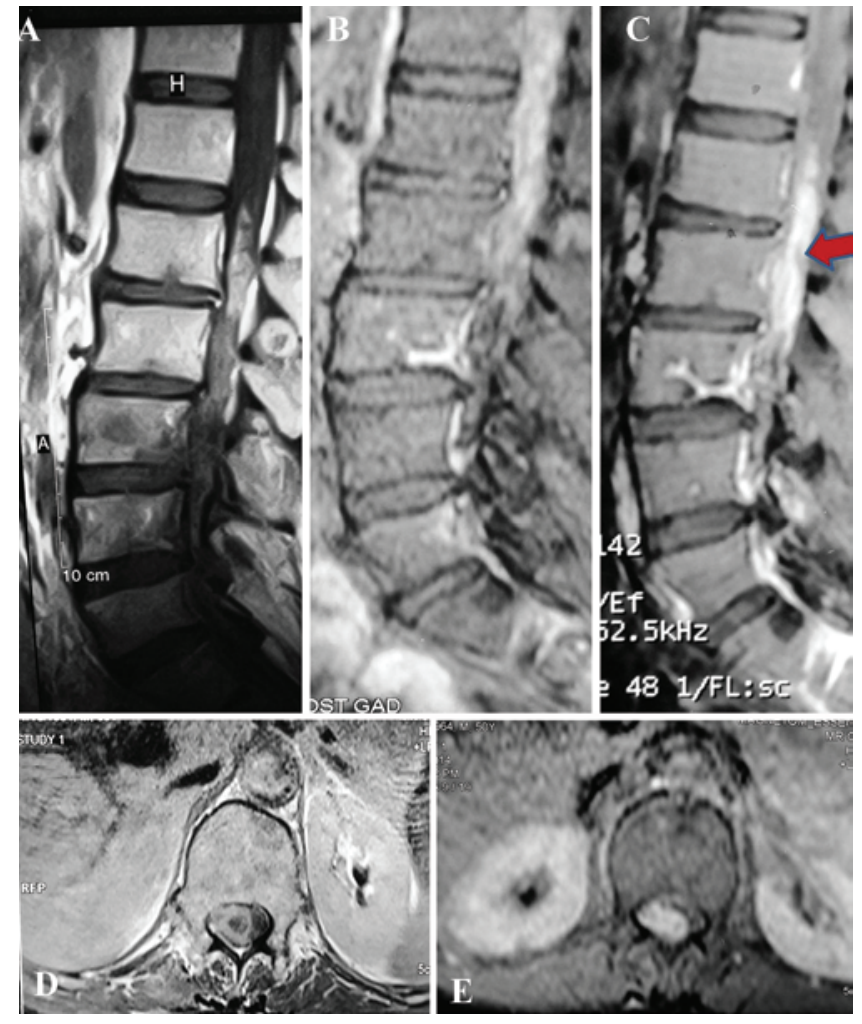

FIG. 1. Case 1. Sagittal T1- (A), T2- (B), and T1-weighted contrastenhanced (C) images showing the ill-defined lesion at L2-3; the lesion is isointense on T1Wl and hypointense on T2WI. On contrast-enhanced imaging, the lesion shows bright irregular enhancement (arrow). Axial T1-weighted plain (D) and contrast-enhanced (E) images showing an intradural lesion compressing the nerve roots to the left side. Figure is available in color online only.

imaging (T2WI), and intensely contrast enhancing after administration of gadolinium. Thecal sac compression was evident. Intraoperatively, after laminectomy, we found an ill-defined lesion beneath a thickened dura. The lesion was firmly adherent to the dura, and no differentiation between normal dura and the lesion could be made out. The lesion was grey in color, firm in consistency, and had ill-defined margins. Subtotal excision was achieved. Histopathological examination suggested IgG4-related pachymeningitis (Fig. 2 and Table 1). The patient was started on a course of steroids, and at follow-up examination 7 months later, he exhibited only marginal improvement in weakness.

\section{Case 2}

A 19-year-old man presented with 1-year history of backache and radiation of pain down to the left lower limb that had been present for 10 days. Examination revealed subtle weakness (Grade 4/5) bilaterally at the knee extensors with no sensory deficits. Results of complete blood count, electrolytes, and renal function tests were within normal limits. MRI showed an ill-defined intradural lesion at L2-3 (Fig. 3A-D). The lesion was isointense on T1WI and hypointense on T2WI and showed dense enhancement after gadolinium administration. The patient underwent L-2 laminectomy, and during surgery the dura was found to be diffusely thickened and hypertrophic, and it showed moderate vascularity. No definite tumor was seen underneath the dura. The margins between normal and abnormal dura were difficult to discern. Since no apparent lesion was seen, a mere biopsy of the thickened tissue was taken. Histopathological examination suggested IgG4-related pachymeningitis (Fig. 4 and Table 1). The patient was started on a course of oral steroids, was pain free at 6 months, and had no additional neurological deficits. Postoperative imaging showed near-complete resolution of the lesion (Fig. 3E-H).

\section{Discussion}

IgG4-related pachymeningitis is a rare disease. The predominant involvement in such cases is of cranial dura and spinal involvement is more rare. Only a handful of case reports are present in the literature. ${ }^{2,11,12}$ Because the disease is relatively new, the definition, diagnostic criteria, treatment protocols, and even nomenclature continue to evolve and are frequently revised/modified. The importance of establishing an early diagnosis lies in the fact that the disease mimics commonly encountered lesions in spinal locations and this can lead to a diagnostic pitfall. Another important factor in favor of an early diagnosis is the multisystem involvement in this disease, which is chronically progressive.

In the present study, both patients presented with features of neural compression at the level of involvement (i.e., myeloradiculopathy in Case 1 and radiculopathy in Case 2). MRI revealed an ill-defined lesion that was isointense on T1WI with intense contrast enhancement. The lesion was hypointense on T2WI. No particular distinguishing radiological features have been described for this disease to distinguish it from malignant lesions. ${ }^{1}$

In both cases the patients were taken to surgery with a preoperative diagnosis of intradural neoplasia (e.g., meningioma/schwannoma/neurofibroma/malignant nerve sheath tumor).

Intraoperatively, no discernable neoplastic lesion was found, but the dura was thickened, hypertrophic, and diffusely involved. Defined borders between normal and abnormal areas were not found. In both cases the lesion was moderately vascular.

IgG4-related pachymeningitis is a histopathological diagnosis and is characterized by a plasma cell-rich inflammatory infiltrate, admixed with variable numbers of eosinophils, storiform fibrosis, and obliterative phlebitis. The plasma cells are predominantly IgG4 positive, and there is an increase in the IgG4:IgG-positive plasma cell ratio. ${ }^{9}$

No consensus exists on the number of IgG4-positive plasma cells required for establishing a diagnosis of IgG4-related pachymeningitis. However, Lindstrom et al. proposed that > $10 \mathrm{IgG} 4$-positive plasma cells/HPF were necessary for a diagnosis of IgG4-related pachymeningitis. ${ }^{6}$ Compared with other organs, obliterative phlebitis is a rare finding in meningeal IgG4-related disease. Important mimics from which this disease should be distinguished include the periphery of an abscess, autoimmune diseases, vasculitis, and any infectious pathology like tuberculosis.

Standard therapeutic regimens are still lacking for the treatment of IgG4-related disease. There are international consensus guidelines on how to manage it. ${ }^{5}$ The summary 


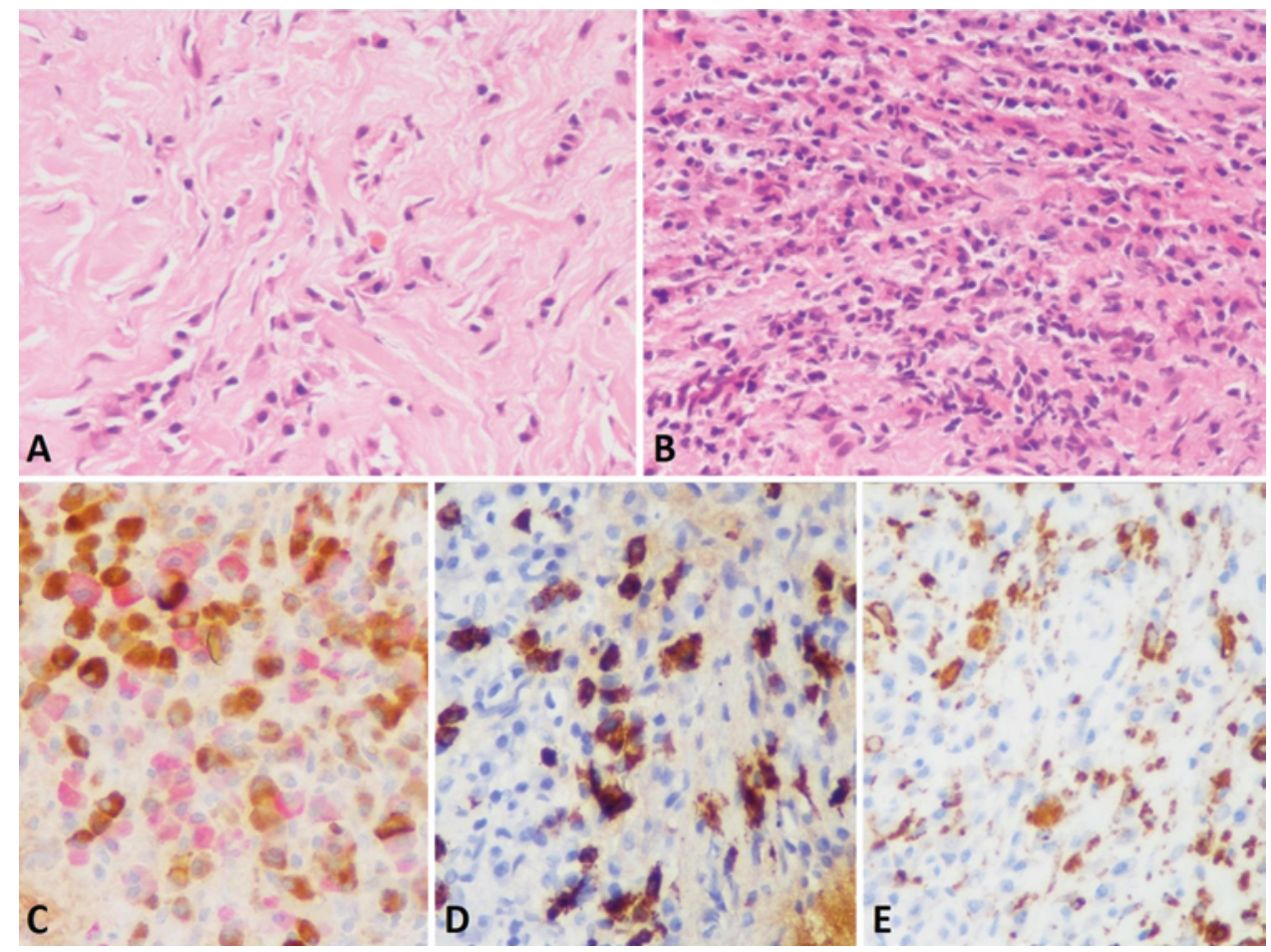

FIG. 2. Case 1. Photomicrographs showing storiform fibrosis admixed with occasional eosinophils $(\mathbf{A})$ and the presence of plasma cell-rich infiltrate (B). $\mathrm{H} \& \mathrm{E}$, original magnification $\times 200$. These plasma cells show positivity for both kappa (red) and lambda (brown), indicating their polyclonal nature (C). Immunoperoxidase, original magnification $\times 400$ (D). Strong IgG4 positivity is seen in the plasma cells $(\mathrm{E})$ and few macrophages are highlighted by CD68 immunostain. Immunoperoxidase, original magnification $\times 400$ ( $D$ and $E$ ). Figure is available in color online only.

includes following: 1) All patients with symptomatic, active IgG4-related disease require treatment. 2) Glucocorticoids are the first-line agent for achieving disease remission. However, the dosage and duration of treatment are still not standardized. 3) If there is relapse, either retreatment with steroids or other immunosuppressive agents may be required.

Immunosuppressive therapy in cases of relapse has been recommended based on an extrapolation from the treatment of other autoimmune conditions. These agents include azathioprine, mycophenolate mofetil, rituximab, and bortezomib.

Although most patients exhibit an initial response to glucocorticoids, the disease follows a progressive course. Clinical response is inversely proportional to the degree of fibrosis.

Spinal decompression provides relief by increasing space for neural elements. In addition, surgery provides adequate tissue for detailed histopathological examination.

\section{Conclusions}

We wish to state that IgG4-related disease is a rare differential diagnosis of leptomeningeal disease. No specific clinical or radiological hallmarks/diagnostic criteria have yet been defined to label the disease. Therefore, the diagnosis rests with histopathological examination, and the pathologist should have high index of suspicion. Although histologically this disease can mimic other inflammatory conditions, the presence of storiform fibrosis and an increased number of IgG4-positive plasma cells can help in confirming the diagnosis. Because the disease is relatively new, its characterization is evolving and newer additions are being made in the literature. Until the time definite

TABLE 1. Histopathological features of IgG4-related spinal pachymeningitis

\begin{tabular}{cccccccc}
\hline & \multicolumn{7}{c}{ Histopathological Feature } \\
\cline { 2 - 8 } $\begin{array}{c}\text { Case } \\
\text { No. }\end{array}$ & $\begin{array}{c}\text { Storiform } \\
\text { Fibrosis }\end{array}$ & $\begin{array}{c}\text { Obliterative } \\
\text { Phlebitis }\end{array}$ & $\begin{array}{c}\text { Plasma Cell-Rich } \\
\text { Infiltrate }\end{array}$ & $\begin{array}{c}\text { Absolute IgG4 Positive } \\
\text { Plasma Cell Count }\end{array}$ & $\begin{array}{c}\text { IgG4:IgG-Positive } \\
\text { Plasma Cell Ratio }\end{array}$ & $\begin{array}{c}\text { Plasma Cell } \\
\text { Clonality }\end{array}$ & Eosinophils \\
\hline 1 & Present & Absent & Moderately dense & $120-130$ & 0.5 & Polyclonal & Occasional \\
\hline 2 & Present & Focally present & Moderately dense & $140-150$ & 0.4 & Polyclonal & Few \\
\hline
\end{tabular}

* Positive cell count per $\times 40$ field. 

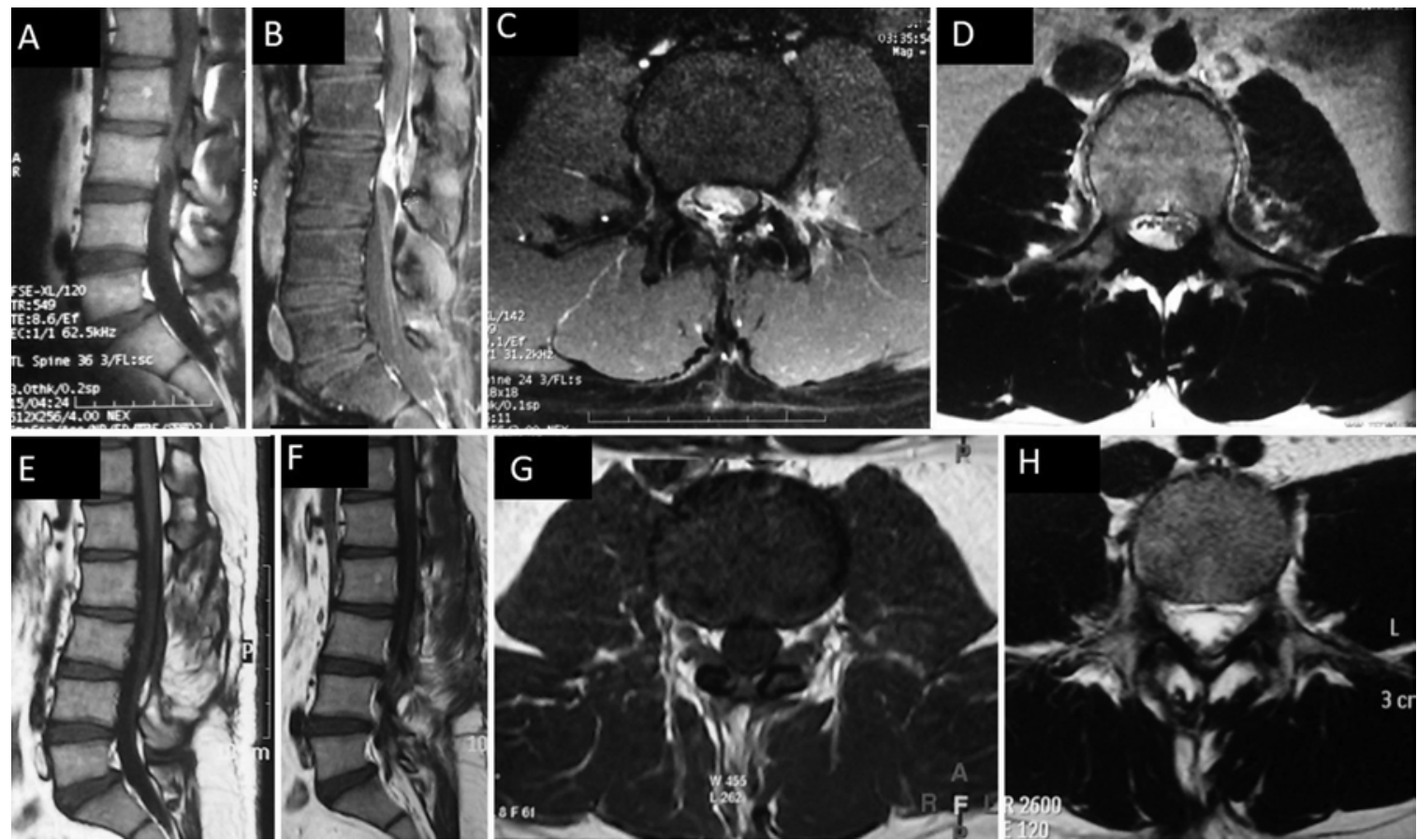

FIG. 3. Case 2. Preoperative (A-D) and postoperative (E-H) images. Sagittal T1-weighted image showing a hypodense lesion at L2-3 (A). Sagittal T1-weighted postcontrast image demonstrating intense contrast enhancement (B). Postcontrast axial T1-weighted image showing the ill-defined, contrast-enhancing lesion (C). Axial T2-weighted image demonstrating the hypodense lesion causing thecal sac compression (D). Sagittal T1-weighted image showing no lesion at the L2-3 level (E). Postoperative changes are seen in the region of the lamina and paraspinal muscles. Sagittal T1-weighted postcontrast image showing no contrast enhancement at the site of the resected lesion (F). Axial T1-weighted postcontrast image showing the absence of a lesion (G). Postoperative changes can be appreciated, for example, on this T2-weighted axial image in which no lesion is seen $(\mathrm{H})$.
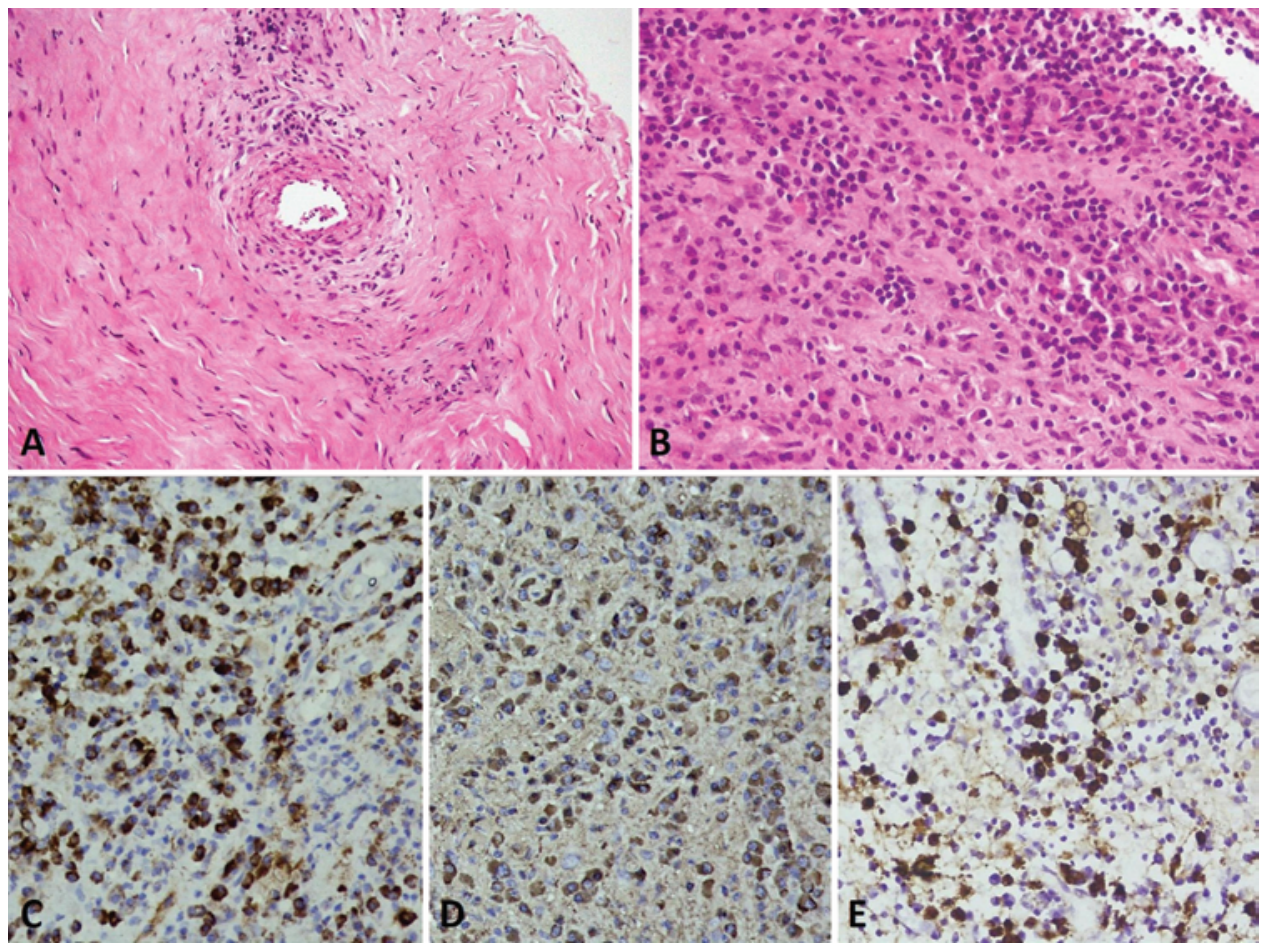

FIG. 4. Case 2. Photomicrograph showing dense fibrosis with obliterative phlebitis (A) and numerous plasma cell infiltrates (B). $H \& E$, original magnification $\times 200$. These plasma cells show positivity for CD138 (C), plasma cells showing positivity for lgG (D), and numerous IgG4 positive plasma cells $(E)$. Immunoperoxidase, original magnification $\times 400$. Figure is available in color online only. 
diagnostic criteria are well established, it is extremely important to accurately diagnose this disease entity since the involvement is multiorgan and the course progressive.

\section{References}

1. Dahlgren M, KhosroshahiA, Nielsen GP, DeshpandeV, Stone JH: Riedel's thyroiditis and multifocal fibrosclerosis are part of the IgG4-related systemic disease spectrum. Arthritis Care Res (Hoboken) 62:1312-1318, 2010

2. Gu R, Hao PY, Liu JB, Wang ZH, Zhu QS: Cervicothoracic spinal cord compression caused by IgG4-related sclerosing pachymeningitis: a case report and literature review. Eur Spine J [epub ahead of print], 2015

3. Kamisawa T, Funata N, Hayashi Y, Eishi Y, Koike M, Tsuruta K, et al: A new clinicopathological entity of IgG4-related autoimmune disease. J Gastroenterol 38:982-984, 2003

4. Kamisawa T, Takuma K, Egawa N, Tsuruta K, Sasaki T: Autoimmune pancreatitis and IgG4-related sclerosing disease. Nat Rev Gastroenterol Hepatol 7:401-409, 2010

5. Khosroshahi A, Wallace ZS, Crowe JL, Akamizu T, Azumi $\mathrm{A}$, Carruthers MN, et al: International consensus guidance statement on the management and treatment of IgG4-related disease. Arthritis Rheumato 167:1688-1699, 2015

6. Lindstrom KM, Cousar JB, Lopes MB: IgG4-related meningeal disease: clinico-pathological features and proposal for diagnostic criteria. Acta Neuropathol 120:765-776, 2010

7. Lu Z, Tongxi L, Jie L, Yujuan J, Wei J, Xia L, et al: IgG4-related spinal pachymeningitis. Clin Rheumatol [epub ahead of print], 2015

8. Okazaki K, Uchida K, Koyabu M, Miyoshi H, Takaoka M: Recent advances in the concept and diagnosis of autoimmune pancreatitis and IgG4-related disease. J Gastroenterol 46:277-288, 2011
9. Saeki T, Saito A, Hiura T, Yamazaki H, Emura I, Ueno M, et al: Lymphoplasmacytic infiltration of multiple organs with immunoreactivity for IgG4: IgG4-related systemic disease. Intern Med 45:163-167, 2006

10. Stone JH, Khosroshahi A, Hilgenberg A, Spooner A, Isselbacher EM, Stone JR: IgG4-related systemic disease and lymphoplasmacytic aortitis. Arthritis Rheum 60:3139-3145, 2009

11. Stone JH, Zen Y, Deshpande V: IgG4-related disease. N Engl J Med 366:539-551, 2012

12. Umehara H: [The Reports of the Grant from the Intractable Disease, Health and Labor Science Research Grants from the Ministry of Health, Labor and Welfare (H21Nanchi-Ippann-112).] Tokyo: Ministry of Health, Labor and Welfare, Japan, 2010 (Jpn)

\section{Disclosures}

The authors report no conflict of interest concerning the materials or methods used in this study or the findings specified in this paper.

\section{Author Contributions}

Conception and design: Singla, Radotra. Analysis and interpretation of data: Radotra, Aggarwal, Kapoor. Drafting the article: Aggarwal, Kapoor. Critically revising the article: Singla, Radotra, Aggarwal. Administrative/technical/material support: Chatterjee.

\section{Correspondence}

Navneet Singla, Department of Neurosurgery, Postgraduate Institution of Medical Education and Research, Chandigarh, Surgery Office, F Block, Level 5 Nehru Hospital, Chandigarh, Pin-160 012, India. email: drnavi2007@yahoo.co.in. 